\title{
Öğretmen Devamsızlık Nedenleri Ölçeğinin Geliştirilmesi
}

\author{
Şerife Türkkan ${ }^{1} \quad$ Öznur Tulunay Ateş ${ }^{2}$
}

\section{Type/Tür:}

Research/Araştırma

Received/Geliş Tarihi: February

26/ 26 Şubat 2020

Accepted/Kabul Tarihi:

DEcember 9/ 9 Aralık 2020

Page numbers/Sayfa No: $123-138$

Corresponding

Author/İletişimden Sorumlu

Yazar:

serife_aksoy_87@hotmail.com

\section{$\checkmark$ iThenticate}

This paper was checked for plagiarism using iThenticate during the preview process and before publication. / Bu çalışma ön inceleme sürecinde ve yayımlanmadan önce iThenticate yazılımı ile taranmıştır.

Copyright $\odot 2017$ by

Cumhuriyet University, Faculty of Education. All rights reserved.

\section{Öz}

$\mathrm{Bu}$ çalışmanın amacı, öğretmenlerin devamsızlık nedenlerini belirlemek için bir ölçek geliştirmektir. Bu amaçla yapılan açımlayıcı ve doğrulayıcı faktör analizleri sonucu iki faktörden ve 28 maddeden oluşan ölçek elde edilmiştir. Açımlayıcı ve doğrulayıcı faktör analizleri sonucunda elde edilen devamsızlık nedenleri ölçeğinde içsel nedenler boyutu 12 maddeden, dışsal nedenler boyutu 16 maddeden oluşmaktadır. Bu araştırmada ölçeğin geçerliği kapsam ve yapı geçerliği bakımından incelenmiştir. Ölçeğin güvenilirliği için Cronbach Alpha güvenilirliği yöntemi kullanılmıştır. Analizlerde ölçeğin, Cronbach Alpha güvenirlik katsayısının ilk uygulamada .94, ikinci uygulamada .92 olduğu ve iki bileşenin birlikte toplam varyansın \%40.10'unu açıkladığı belirlenmiştir. Doğrulayıcı faktör analizi çalışmaları sonucuna göre, uyum indeksleri; $\mathrm{X}^{2} / \mathrm{sd}=3.41$, GFI (.82), CFI (.95), NFI (.93), RMSEA (.08), AGFI (.79), SRMR (.06), p (.00) şeklinde hesaplanmıştır ve uyum indekslerinin yeterli aralıkta olduğu görülmüştür. Yapılan geçerlik ve güvenilirlik analizleri, ölçeğin öğretmenlerin devamsızlık nedenlerini ölçebileceğini göstermiştir. Geliştirilen ölçeğin bu konudaki araştırmalarda kullanılabilmesi ve yapılacak yeni çalışmaları arttırabilmesi beklenmektedir.

Anahtar Kelimeler: Öğretmen devamsızlığı, öğretmen devamsızlık nedenleri, devamsızlığın içsel nedenleri, devamsızlığın dışsal nedenleri, öğretmen devamsızlık nedenleri ölçeğinin geliştirilmesi.

\section{Suggested APA Citation/Önerilen APA Atıf Biçimi:}

Türkkan, Ş., \& Tulunay-Ateş, Ö. (2021). Öğretmen devamsızlık nedenleri ölçeğinin geliştirilmesi. Cumhuriyet International Journal of Education, 10(1), 123-138. http://dx.doi.org/10.30703/cije.694533

\footnotetext{
1 Öğretmen, Tefenni Anadolu İmam Hatip Lisesi, Burdur/Türkiye Teacher, Tefenni Anatolian Imam Hatip High School, Burdur/Turkey e-mail: serife_aksoy_87@hotmail.com_ORCID ID: 0000-0003-1845-998X

2 Doçent, Burdur Mehmet Akif Ersoy Üniversitesi, Burdur/Türkiye Assoc. Prof. Burdur Mehmet Akif Ersoy University, Burdur/Turkey e-mail: otates@mehmetakif.edu.trＯRCID ID: 0000-0003-1784-7227

Bu araştırma birinci yazarın ikinci yazar danışmanlığında hazırladığı yüksek lisans tezinin bir kısmından üretilmiş olup Mehmet Akif Ersoy Üniversitesi Bilimsel Araştırma Projeleri Komisyonu tarafından 0457-YL-17 nolu proje numarası ile desteklenmiştir.
} 


\title{
Developing the Causes of Teacher Absenteeism Scale
}

\begin{abstract}
The aim of this study is to develop a scale to determine the causes of teacher absenteeism. For this purpose, as a result of the exploratory and confirmatory factor analysis, a scale which consists of two factors and 28 items was obtained. In this study, validity of the scale was examined in terms of the content and construct validity. In the scale of causes of absenteeism which was obtained as a result of the exploratory and confirmatory factor analyses, the dimension of the internal causes of absenteeism consists of 12 items, the dimension of the external causes of absenteeism consists of 16 items. Cronbach Alpha reliability method was used for reliability of the scale. In the analyses, it was determined that the Cronbach Alpha reliability coefficient of the scale was .94 in the first application, .92 in the second application and two components explained $40.10 \%$ of the total variance together. According to the results of confirmatory factor analysis studies, fit indices were calculated such as: $\mathrm{X}^{2} / \mathrm{sd}=3.41$, GFI (.82), CFI (.95), NFI (.93), RMSEA (.08), AGFI (.79), SRMR (.06), p (.00) and it was seen that fit indices were in a sufficient range. The validity and reliability analyses showed that the scale can measure the causes of teacher absenteeism. It is expected that the developed scale can be used in the research on this issue and can increase new studies to be done.
\end{abstract}

Keywords: Teacher absenteeism, causes of teacher absenteeism, the internal causes of absenteeism, the external causes of absenteeism, developing the causes of teacher absenteeism scale.

\section{Giriş}

Devamsızlık kavramı birçok araştırmacı tarafından farklı biçimlerde tanımlandığı için alanyazında tüm araştırmacıların üzerinde uzlaştığı ortak bir devamsızlık tanımına rastlamak zordur (Erdemli ve Güner-Demir, 2015, s. 420). Araştırmalarda devamsızlık konusunda genelde işe devamsızlık kavramının kullanıldığı görülmektedir. En genel tanımıyla işe devamsızlık, çalışanın fiziksel olarak iş yerinde bulunmamasıdır (Şahin, 2011). Öğretmen devamsızlığı kavramı ise; genellikle hastalık, yaralanma, kişisel gereksinim sonucu olarak işten uzaklaşılan bir günü ifade eder ve herhangi bir zamanda izinli veya izinsiz işten uzak olmak anlamına gelir (Hovey, 1999, s. 24).

Bazı araştırmacılar tarafından; devamsızlık probleminin farklı boyutlarını ele alan kapsamlı teorik çerçevenin yetersizliğinin bu olgunun sistematik olarak çalışılması üzerine olumsuz etkisi olduğu (As, 1962; Steers ve Rhodes, 1978) dile getirilmektedir. Az da olsa alanyazında devamsızlık modelleri üzerine yapılan bazı araştırmalar bulunmaktadır. Bu araştırmalarda farklı etkenlerin işçilerin işe gelme ya da işe devamsızlık yapma kararını nasıl etkilediğini daha iyi açıklamak için çeşitli modeller geliştirilmiştir. Bunlara örnek olarak; Gibson (1966), Steers ve Rhodes (1978) ve Nicholson ve Johns (1985) modelleri verilebilir.

Araştırma kapsamında özellikle, Steers ve Rhodes (1978) modelinden, Robinson'un (2008, s. 48) kişisel ve mesleki devamsızlık ayrımından ve içsel ve dışsal motivasyon kuramından (Ryan ve Deci, 2000) yararlanılmışır. İlgili model ve kuramlar incelendiğinde Steers ve Rhodes (1978) modelinin devamsızlı nedenlerini "işe gitme isteği" ve işe gidebilme imkanı" şeklinde ikiye ayırdığı görülmektedir. Bu modelde "İşe gitme isteği" daha çok çalışanın işi ve örgütü üzerindeki duygu ve düşünceleriyle biçimlenmektedir (Şahin, 2011). "İşe gitme istekliliğinin" içerdiği bazı faktörler; iş durumu, iş doyumu, iş alanı, iş düzeyi, rol stresi, iş grubu büyüklügüu, liderlik stili, meslektaş ilişkileri, terfi için fırsatlar, işgören değerlerinin rolü, iş beklentileri, devam baskısı, ekonomik ve pazar şartları, ödül sistemi, iş grubu normları, kişisel iş etiği ve örgütsel bağlllık şeklinde sıralanabilir. "İşe gidebilme 
imkanı" ise hastalık, kazalar, ailevi sorumluluklar ve ulaşım problemleri faktörlerini içermektedir (Steers ve Rhodes, 1978). Bu model öğretmen devamsızlı̆̆ ile ilgili en fazla atıf alan modeldir (Brown ve Arnell, 2012; Harrison ve Martocchio, 1998). Psikolojik, örgütsel ve ekonomik disiplinlerin devamsızlık araştırmalarının deneysel sonuçları ve kuramlarını birleştiren en eski ve kapsamlı modellerden biridir (Habib, 2010, s. 44). Robinson (2008, s. 48) ise, yaptığı araştırmada öğretmen devamsızlığını kişisel ve mesleği ile ilgili devamsızlık olmak üzere ikiye ayırmıştır. Kişisel devamsızlık öğretmenin kişisel nedenlerden dolayı okulda bulunmamasıdır. Örneğin, öğretmenin kendisinin hastalığı, aile üyelerinden birinin hastalığı, ailede ölüm, çocuğunun mezuniyetine katılmak, ev taşımak gibi çeşitli nedenlerden dolayı okula gitmemeye karar vermesidir. Mesleği ile ilgili devamsızlık ise öğretmenin okul ya da resmi merci tarafından verilen görevler nedeniyle okulda bulunmamasıdır. Örneğin, öğretmenin komite oturumları, toplantılar, mesleki gelişim, konferans, jüri görevi gibi nedenlerden dolayı okula gelmemesidir. İçsel ve dışsal motivasyon kuramında (Ryan ve Deci, 2000) ise, dişsal motivasyon kişinin diştan kontrol edildiğini vurgularken, içsel motivasyon motive olmanın birinci kaynağı olarak, içsel düşünceleri ve duyguları vurgulamaktadır. Araştırmadaki devamsızlık nedenlerindeki içsel nedenler bireyin motivasyonunu sağlayan iç güçlerle, dişsal nedenler bireyin motivasyonunu sağlayan dış güçlerle ilişkilendirilebilir. Bu üç kuramsal bilginin, kişisel-içsel ve dişsal-mesleki ayrımı bağlamında aralarında benzerlikler barındırdığı söylenebilir.

Eğitimin niteliğini ve etkililiğini olumsuz yönde etkileyen iki önemli problemden birincisinin öğretmen devamsızlığı ve ikincisinin de öğretmenlerin iş gücü devri olduğu (Chapman, 1994) görüşünden hareketle, eğitimin kalitesi ve verimliliği ile bu kadar yakından ilişkili olan öğretmen devamsızlığı konusunda bir ölçeğin geliştirilmemiş olmasının alanyazında büyük bir eksiklik olduğu görülmektedir. Dünya Bankası'nın (2011, s. 18) raporuna göre Türkiye'de öğretmenlerin devamsızlık oranı (\%35) ve işe geç gelme oranı (\%31) OECD ortalamasının üzerindedir. Bu bilgilerden hareketle Türkiye'de de öğretmen devamsızlığının eğitim örgütlerinde önemli bir problem haline gelmeye başladığı söylenebilir. Öğretmen devamsızlığını önlemek için öğretmen devamsızlık nedenlerinin tespit edilmesi ve bu nedenlere göre çözüm yollarının aranması gerektiği düşünülmektedir. Eğitimin kalitesini olumsuz yönde etkileyen öğretmen devamsızlı̆̆ konusunda araştırma yapmak ve araştırmaları arttırmak için geçerli ve güvenilir bir ölçeğin geliştirilmesine ihtiyaç duyulduğu söylenebilir.

Yapılan incelemelerde Türkiye'de öğretmen devamsızlığının sınırlı sayıda araştırmaya (Bakay, 2014; Sezgin vd., 2014) konu olduğu ve verilerin ölçekle toplanmadığı görülmüştür. Bakay'ın (2014) yaptığı araştırmada; öğretmenlerin devamsızlık oranlarının cinsiyete, yaşa, okulun yerleşim yerine, öğretim şekline ve türüne göre anlamlı farklılık gösterdiği tespit edilmiştir. Sezgin vd. (2014) ise, okul müdürlerinin görüşlerine göre öğretmen devamsızlık nedenlerini nitel yöntemle incelediği araştırmada; öğretmenlerin aylık olarak daha fazla devamsızlık yaptığını, devamsızlığa neden olan başlıca kişisel etkenlerin sağlık problemleri, aile problemleri olduğunu ve en önemli örgütsel faktörün negatif okul iklimi olduğunu belirtmiştir. Türkiye'de yapılan araştırmalarda (Bakay, 2014; Sezgin vd., 2014) öğretmen devamsızlık nedenlerini belirlemek için geliştirilen bir ölçeğe rastlanmamıştır. Alanyazındaki bu boşluğu doldurma ihtiyacı doğmaktadır. Bu konuda yapılacak 
bilimsel çalışmalara katkı sağlamak istenmektedir. $\mathrm{Bu}$ araştırmanın amacı, öğretmenlerin devamsızlık nedenlerini belirlemek için bir ölçek geliştirmektir.

\section{Çalışma Grubu}

\section{Yöntem}

$\mathrm{Bu}$ araştırmada çalışma grubu kolay ulaşılabilir örneklem yöntemi ile belirlenmiştir. Kolay örnekleme vakit, maddiyat ve iş gücü bakımından mevcut sınırlılıklar sebebiyle örneklemin kolay ulaşılabilir ve uygulama yapılabilir birimlerden tercih edilmesidir (Büyüköztürk, 2012). Kolay ulaşılabilir örnekleme yönteminin sınırlılıkları da vardır. Kolay örnekleme yöntemi ile ulaşılan verilerin kuşku ile değerlendirilmesi gerekir. Örneklemin evreni temsil etme gücü düşüktür. Ulaşılan bulguların geneli temsil ettiği iddia edilmemelidir (Altunışık, Coşkun, Bayraktaroğlu ve Yıldırım, 2010, s. 130).

Tarama modelinde yürütülen bu araştırma, kolay ulaşılabilir örneklem yöntemiyle 2017-2018 yılında Antalya ve Burdur ilinde gerçekleştirilmiştir. Araştırma süreci ardışık aşamalarla gerçekleştirilmiştir. Araştırma sürecinin ilk aşamasında Burdur'un Tefenni İlçesi'nde 13 öğretmen ile öğretmen devamsızlık nedenleri hakkında görüşme yapılmış, ikinci aşamasında Tefenni ve Çavdır ilçelerinde 54 öğretmen ile deneme uygulaması yapılmıştır. Üçüncü aşamasında Antalya ilindeki 415 öğretmenin verisi ile Açımlayıcı Faktör Analizi (AFA) yapılmıştır. Kline (1994) mutlak ölçüt olarak 200 kişilik örneklemin yeterli olduğunu ama daha iyi sonuçlar için örneklem büyüklüğünün madde sayısının 10 katı kadar olmasını önerir. Bu araştırmada ölçekte yer alan 42 madde sayısının yaklaşık 10 katı olan 415 katılımcıdan elde edilen veriler ile açımlayıcı faktör analizi yapılmıştır. Bu nedenle, araştırmada ölçek geliştirmek için yeterli örneklem büyüklüğüne ulaşıldığı söylenebilir. Son aşamada ise Burdur ilindeki 380 öğretmenin verisi ile Doğrulayıcı Faktör Analizi (DFA) yapılmıştır. Çalışma grubunun devamsızlık yaptığı varsayılarak ölçek bu grup üzerinde geliştirilmiştir.

\section{Öğretmen Devamsızlık Nedenleri Ölçeği Geliştirme Süreci}

Öğretmen Devamsızlık Nedenleri Ölçeği'nin geliştirilme sürecinde ilk olarak konu hakkında alanyazın taraması yapılmıştır. Daha sonra Burdur'un Tefenni İlçesi'nde 13 öğretmen ile öğretmen devamsızlık nedenleri hakkında görüşme yapılmıştır. Yapılan görüşmelerden ve alanyazın taraması sonuçlarından yararlanılarak 50 maddeden oluşturulan taslak ölçeğin kapsam geçerliliği için Ölçme ve Değerlendirme ve Eğitim Yönetimi alanından beş uzmanın görüşüne başvurularak; yeterince anlaşılır bulunmayan maddeler düzeltilmiş ve herkes için geçerli olmayacağı kanaatiyle üç madde ölçekten çıkarılmıştır. Geliştirilen ölçme aracında beşli Likert tipi derecelendirme ölçeği kullanılmıştır. Ölçek: (1) Kesinlikle katılmıyorum, (2) Katılmiyorum, (3) Kismen katılıyorum, (4) Katılıorum, (5) Kesinlikle katıliyorum şeklinde derecelendirilmiştir.

Ölçeğin deneme uygulamasında 54 kişiden elde edilen veriler ile ölçeğin madde toplam korelasyonlarına bakılmıştır. Büyüköztürk (2017, s. 183)'e göre madde toplam korelasyon katsayısı .20'nin altında olan maddeler ölçme aracından çıkarılması gerekmektedir ve .20 - .30 arasında olan maddeler zorunlu ise ölçme aracına alınabilir. $\mathrm{Bu}$ aşamada deneme uygulaması olması nedeniyle .20'nin altındaki maddelerin çıkarılması uygun görülmüştür. Madde toplam korelasyonlarının .30 ve üzerinde olması maddelerin bireyleri iyi ayırt ettiğini göstermektedir (Büyüköztürk, 2017, s. 
183). Bu nedenle ölçeğin asıl uygulamasında faktör analizi öncesinde 415 kişinin verisi ile tekrarlanan analizlerde madde toplam korelasyon değerleri .30' un altında olan 4 madde ölçekten çıkarılmıştır.

\section{Verilerin Analizi}

Araştırmada verilerin açımlayıcı faktör analizine uygun olup olmadığ Kaiser-MeyerOlkin (KMO) örneklem yeterliliği ve Barlett Küresellik testleri ile incelenmiştir. Ölçeğin yapı geçerliliğini belirlemek amacıyla açımlayıcı faktör analizi (AFA), bu analiz neticesinde elde edilen faktör yapısının doğruluğunu test etmek amacıyla Doğrulayıcı Faktör Analizi (DFA) yapılmıştır. Açımlayıcı faktör analizi (AFA) Antalya il merkezinde görev yapan kolay ulaşılabilir örnekleme yöntemiyle belirlenen 428 katılımcının verileri ile yapılmıştır. Verilerdeki uç, eksik ve hatalı değerler incelenmiş; aynı cevap seçeneklerinin işaretlendiği ve boş bırakılan 13 kişiye ait form normalliği etkileyeceği düşüncesiyle çıkarılmış ve 42 maddelik ölçekle ve 415 katılımcıdan elde edilen veriler ile AFA gerçekleştirilmiştir. Doğrulayııı faktör analizi (DFA) ise, Burdur il merkezinde görev yapan kolay ulaşılabilir örnekleme yöntemiyle belirlenen 380 öğretmenle gerçekleştirilmiştir. Ölçeğin kapsam geçerliliği için uzman görüşüne başvurulmuştur. AFA'da ulaşılan ölçeğin model uyumu DFA yapılarak incelenmiştir. DFA' da çoklu uyum indeksleri kullanılmıştır. Ölçeğin güvenirliğinin incelenmesinde ise iç tutarlılık katsayısı hesaplanmıştır.

\section{Geçerlik}

\section{Bulgular}

Büyüköztürk'e (2017, s. 179) göre geçerlik teknikleri içinde en çok tercih edilenleri kapsam geçerliği, ölçüt bağımlı geçerlik ve yapı geçerliliğidir. Bu araştırmada ölçeğin geçerliği kapsam ve yapı geçerliği bakımından incelenmiştir. Kapsam geçerliği için ölçek geliştirme sürecinde uzman görüşüne başvurulmuş, yapı geçerliliğinde faktör analizi yapılmıştır.

Yapı geçerliliği. Faktör analizi yapmadan önce ölçeğin madde toplam korelasyonlarına bakılmıştır. Yapılan analizler sonucunda ulaşılan bulgular Tablo 1' de verilmiştir.

Tablo 1'de ölçekte bulunan 42 maddenin ölçülmek istenen özelliği ölçüp ölçmediğini saptamak için yapılan madde analizi değerleri incelendiğinde; 1, 2, 12, 15 . maddelerin madde toplam korelasyonlarının .30'un altında olduğu görülmüştür. 
Tablo 1.

Madde Analizi Sonuçları

\begin{tabular}{llll}
\hline Maddeler & Madde Toplam Korelasyonu & Maddeler & Madde Toplam Korelasyonu \\
\hline M1 & .15 & M22 & .42 \\
M2 & .18 & M23 & .64 \\
M3 & .41 & M24 & .60 \\
M4 & .51 & M25 & .56 \\
M5 & .32 & M26 & .56 \\
M6 & .50 & M27 & .58 \\
M7 & .50 & M28 & .61 \\
M8 & .51 & M29 & .49 \\
M9 & .59 & M30 & .58 \\
M10 & .56 & M31 & .62 \\
M11 & .57 & M32 & .61 \\
M12 & .15 & M33 & .44 \\
M13 & .57 & M34 & .54 \\
M14 & .57 & M35 & .56 \\
M15 & .05 & M36 & .61 \\
M16 & .52 & M37 & .55 \\
M17 & .60 & M38 & .54 \\
M18 & .62 & M39 & .55 \\
M19 & .68 & M40 & .43 \\
M20 & .63 & M41 & .56 \\
M21 & .58 & M42 & .37 \\
\hline
\end{tabular}

Açımlayıcı faktör analizi. Alanyazında faktör analizi yapmak için yeterli sayılacak örneklem sayısı üzerine çeşitli yorumlar yapılmıştır (Can, 2016, s. 319). Örneğin, Bryman ve Cramer (2001) madde sayısının 5 ya da 10 katı kadar olmasını önerir. Bu araştırmada ölçekte yer alan 42 madde sayısının yaklaşık 10 katı olan 415 katılımcıdan elde edilen veriler ile AFA yapılmıştır.

Araştırmada verilerin faktör analizine uygun olup olmadığı Kaiser-MeyerOlkin (KMO) örneklem yeterliliği ve Barlett Küresellik testleri ile incelenmiştir. KMO testi, örneklem yeterliliğini gösterir ve .70 ve üzeri iyi olarak değerlendirilir (Can, 2016, s. 325). Verilerin çok değişkenli normal dağılımdan geldiği Barlett Küresellik Testi ile bulunur (Çokluk, Şekercioğlu ve Büyüköztürk, 2010, s. 208). Örneklem büyüklüğü için ise, KMO değeri .90 üzerinde ise 'mükemmel' yorumu yapılır (Tavşancıl, 2010, s. 50). Yapılan analizlerde Kaiser-Meyer-Olkin (KMO) değerinin .93 olması ve Barlett Küresellik testinin anlamlı bulunması $\left(x^{2}=7937.860, \mathrm{sd}=861, \mathrm{p}=.000\right)$ verilerin AFA için uygun olduğunu göstermiştir. Verilerin faktör analizine uygunluğu saptandiktan sonra, ölçeğin yapı geçerliliğini test etmek için AFA yapılmıştır. AFA'da öncelikle, ortak varyans tablosunda her bir maddenin ortak bir faktördeki varyansı birlikte açıklama oranları ve her maddenin açıkladığı varyans değerini gösteren değerler incelenmiştir. Maddelerin faktörlerce açıklanan ortak varyansın .10' dan düşük olması durumunda, bu maddelerle alakalı bir problem olma ihtimali yüksektir (Çokluk vd., 2010, s. 220). Araştırmada .10'dan küçük olan bir madde olmadığı için maddelerin herhangi birinde sorun olmadığı düşünülmüştür. 
Ölçeğin yapı geçerliliğini belirlemek için varimax dik döndürme yöntemi kullanılarak AFA yapılmıştır. Araştırmacı bir faktör analizi tekniğini kullanarak ulaştı̆̆ı "m" kadar faktörü, "bağımsızlık, yorumlamada açıklık ve anlamlılık" sağlamak için bir eksen döndürmesi yapabilir (Brown, 2006, akt. Çokluk vd., 2010, s. 201). Dik ve eğik döndürme olmak üzere iki tür yaklaşım mevcuttur. Daha basit yorumlanabilir olması sebebiyle sosyal bilimlerde ölçek geliştirmede genellikle dik döndürme tercih edilmektedir (Büyüköztürk, 2017, s. 136). Araştırmada AFA öncesinde yapılan incelemelerde, ortalama (2.71), ortanca (2.69) ve tepe değerin (2.40) birbirine yakın olduğu görülmüştür. Histogram grafiğinin simetrik çan eğrisine benzediği, çarpıklık (.06) ve basıklık (-.12) katsayılarının değerlerinin sıfıra yakın olduğu belirlenmiştir. Can $(2016$, s. 82) ortalama, ortanca ve tepe değer birbirine yakın olmasının, histogram grafiğinin simetrik çan eğrisine benzemesinin, çarpıklık ve basıklık katsayısının sıfıra yakın olmasının verilerin normal dağılım gösterdiğinin belirtisi olduğunu ifade etmiştir. Bu nedenle verilerin normal dağılım gösterdiğine karar verilmiştir.

Ölçeğin kaç faktör altında toplandığını tespit etmek için özdeğer ve çizgi grafiğinden yararlanılmaktadır. Çizgi grafiğinde yatay eksen faktörleri, dikey eksen özdeğerleri göstermektedir. Grafik, faktörlerin özdeğerleriyle eşleştirilmesi neticesinde bulunan noktaların birleştirilmesiyle oluşturulmaktadır. Grafikte yüksek ivmeli, hızlı düşüşlerin olduğu faktör, önemli faktör sayısını göstermektedir (Büyüköztürk, 2017, s. 135-136). Şekil 1'de faktör öz değerlerine ait çizgi grafiği görülmektedir.

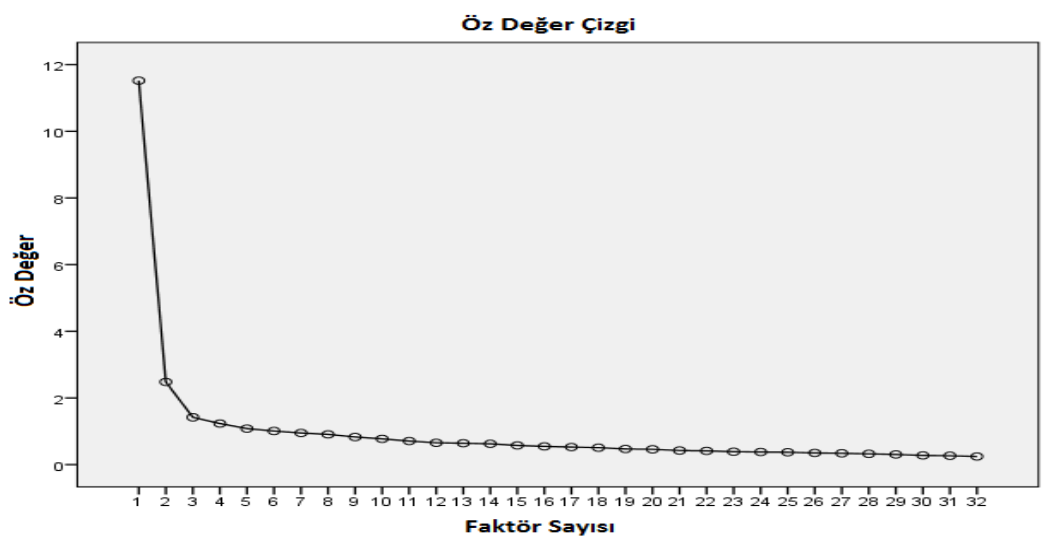

Şekil 1. Özdeğer çizgi grafiği

Şekil 1'de gösterilen faktörlere ait özdeğer çizgi grafiği incelendiğinde, ikinci faktörde bir kırılma noktası olduğu ve grafikte bu noktadan sonra bir düşüş olduğu görülmüştür. Faktör sayısına karar vermenin bir diğer yolu da öz değere bakmaktır. Bir faktör ile ilgili maddelerin faktör yüklerinin karelerinin toplamı o faktöre ilişkin özdeğer olarak isimlendirilir (Can, 2016, s. 317). Özdeğer, faktörlerce açılanan varyansı hesaplamada ve faktör sayısına karar vermede önemsenen bir katsayıdır ve faktör analizinde öz değeri 1 ve 1'den büyük olan faktörler önemli faktörler olarak kabul görür (Büyüköztürk, 2017, s. 135). AFA sonucunda ölçek verilerinin özdeğeri 1'den büyük 2 faktör altında toplandığ tespit edilmiştir. Bu nedenlerle; ölçekteki faktör sayısının iki ile sınırlandırılarak analizlerin tekrar edilmesine karar verilmiştir. 
Faktörler tespit edildikten sonra maddelerin hangi faktörde bulunduğunu tespit etmek için faktör analizi yapılmıştır. Faktörleri oluşturan maddeler, faktör yük değerleri, ölçeğin son halinin özdeğer ve varyans oranları Tablo 2 ' de verilmiştir.

Tablo 2.

Öğretmen Devamsızlık Nedenleri Ölçeği AFA Sonuçları

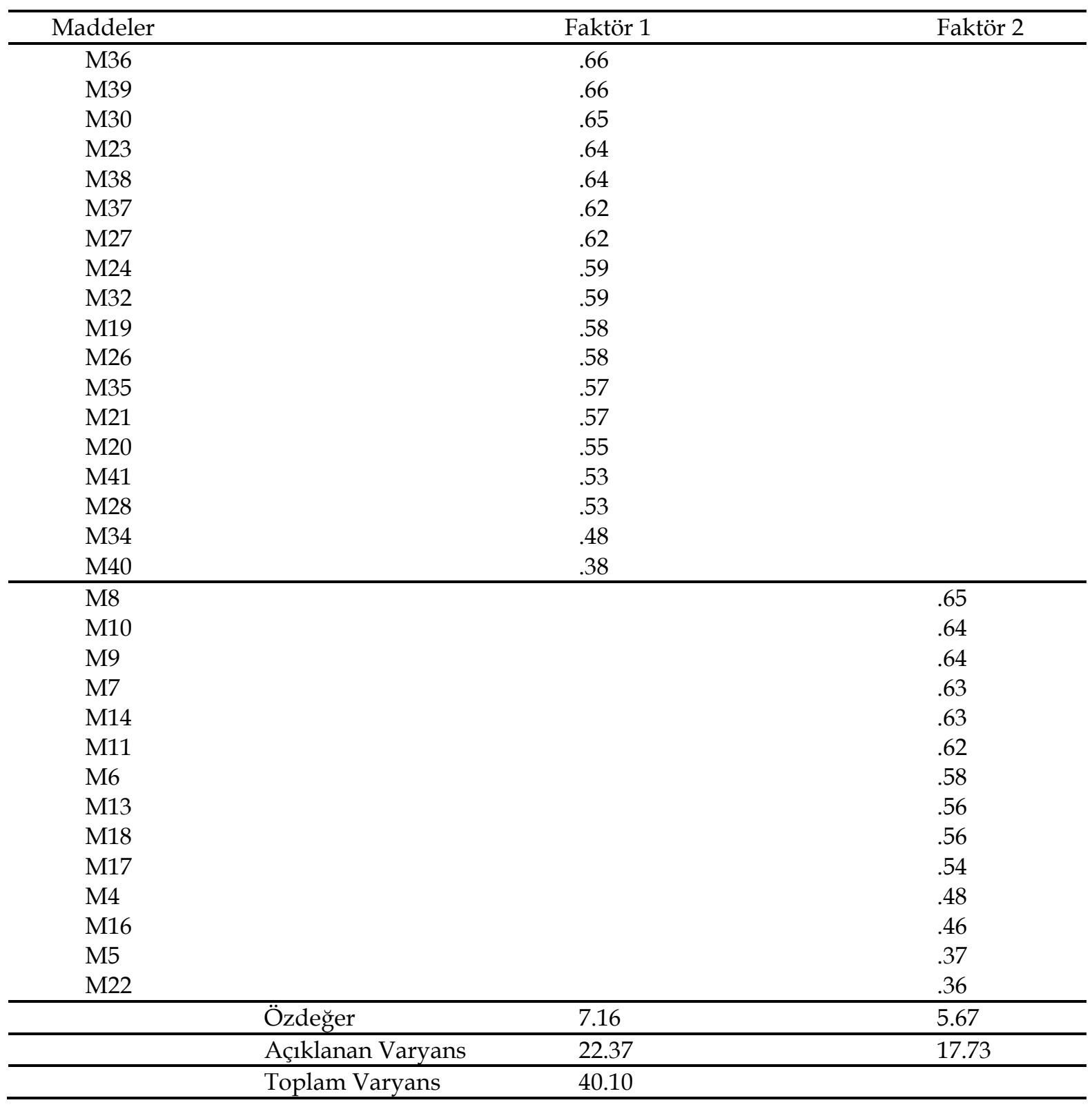

Tablo 2' de görüldüğü üzere maddelerin faktör yük değerleri .36 ile .66 arasında değişmektedir. Faktör yük değerinin .45 ve üstü olması iyi bir ölçüdür ama az sayıda madde için bu sınır değer .30'a kadar düşürülebilir (Büyüköztürk, 2017, s. 134). Tabachnick ve Fidell (2001) temel kaide olarak her bir değişkenin yük değerinin .32 ve üzerinde değerlendirilmesi gerektiğini ileri sürer. Ölçekten madde çıkarılması konusunda dikkate alınan diğer bir husus ise maddelerin binişik olup olmamasıdır. $\mathrm{Bu}$ nedenle, yapılan değerlendirmeler ve tekrarlı uygulamalar neticesinde AFA'da binişik, faktör yük değeri .30 'un altında olan ve hiçbir faktöre girmeyen maddeler 
olmak üzere toplam 6 madde $(3,25,29,31,33,42)$ ölçekten teker teker çıkarılmıştır. İlgili maddeler çıkarıldıktan sonra; toplam varyansın \%22.37'sini açıklayan birinci faktör dışsal nedenler, \%17.73'ünü açıklayan ikinci faktör içsel nedenler olarak adlandırılmıştır. İçsel ve dişsal nedenler olarak adlandırılan iki faktör toplam varyansın \%40.10'unu açıklamaktadır. Scherer, Wiebe, Luther ve Adams (1988) sosyal bilimlerde açılanan varyansın $\% 40$ ile \%60 arasında olmasının yeterli olduğunun kabul görüldüğünü bildirmişlerdir (akt. Tavşancil, 2010, s. 48).

Araştırmada devamsızlık nedenlerinin içsel ve dişsal nedenler şeklinde iki boyuta ayrılmasına öğretmenlerle yapılan görüşmeler sonucunda elde edilen veriler 1şığında karar verilmiştir. Dişsal nedenler boyutu mesleki, okulla ilgili ve paydaşlarla ilgili problemlerden kaynaklanan nedenleri kapsamaktadır. İçsel nedenler boyutu psikolojik etkenleri, kişisel sorunları ve tepkisel nedenleri kapsamaktadır. Dışsal nedenler boyutunda 4 madde mesleki, 7 madde okulla ilgili, 7 madde paydaşlarla ilgili problemlerden kaynaklanan nedenleri içermektedir. İçsel nedenler boyutunda ise 3 madde psikolojik etkenleri, 8 madde kişisel sorunları, 3 madde tepkisel nedenleri içermektedir. $\mathrm{Bu}$ boyutlardan dişsal nedenlerin genelde; öğretmenlerin devamsızlıklarına neden olan olanaksızlıkları, olumsuz şartları ve durumları ifade ettiği, içsel nedenlerin ise; istek, eğilim ve arzularını yansıttı̆̆ı söylenebilir.

Doğrulayıcı faktör analizi. Doğrulayıcı Faktör analizi, faktörler arasında yeterli seviyede ilişkinin var olup olmadığını, hangi değişkenlerin hangi faktörlerle ilişkili olduğunu, faktörlerin birbirlerinden bağımsız olup olmadığını, faktörlerin modeli açıklamakta yeterli derecede olup olmadı̆̆ını denemek amacıyla kullanılır (Özdamar, 1999).

Ölçeğin iki faktörden oluşan yapıya sahip olduğunu doğrulamak amaciyla doğrulayıcı faktör analizi (DFA) Burdur il merkezinde görev yapan kolay ulaşılabilir örnekleme yöntemiyle belirlenen 380 öğretmenle gerçekleştirilmiştir. Öğretmen devamsızlık nedenleri ölçeğine ilişkin DFA uygulaması Şekil 2'de, DFA uyum değerleri Tablo 2'de verilmiştir.

Yapılan DFA analizinde, tüm maddelerin standardize edilmiş ilişki katsayılarının (.20 - .69) arasında değiştiği görülmüştür. 31. maddenin (hata oranı=.96; $\mathrm{r}=.20 ; \mathrm{t}=3.78$ ), 22. maddenin (hata oranı= .90; $\mathrm{r}=.32 ; \mathrm{t}=6.17$ ) değerlerinde olduğunun, 31. madde dışındaki maddelerin geçerli olduğunun ( $r>30)$, modifikasyon indeksleri incelendiğinde ise, 3. maddenin diğer boyutla ilişkili olduğunun ve 30. maddenin (hata oranı=.86; $\mathrm{r}=.37 ; \mathrm{t}=7.23$ ) değerlerinin sınırlara yakın olduğunun görülmesi üzerine bu maddelerin çıkarılmasına karar verilmiştir. Madde 6 (maddeler çıkarıldıktan sonra ölçeğin son formunda madde 5) "Okulun araç, gereç ve donanım yönünden eksikleri olduğunda okula gitmek istemem." ile madde 7'nin (son formda madde 6) "Okulda 1sınma problemi olduğu zaman okula gitmek istemem." ölçekte aynı gizil değişken altında yer alması ve birbiriyle ilişkili olması nedeniyle maddeler arasında modifikasyon verilmesine karar verilmiştir. Yapılan değişiklikler sonundaki DFA analizi sonuçları Şekil 2' de verilmiştir. 


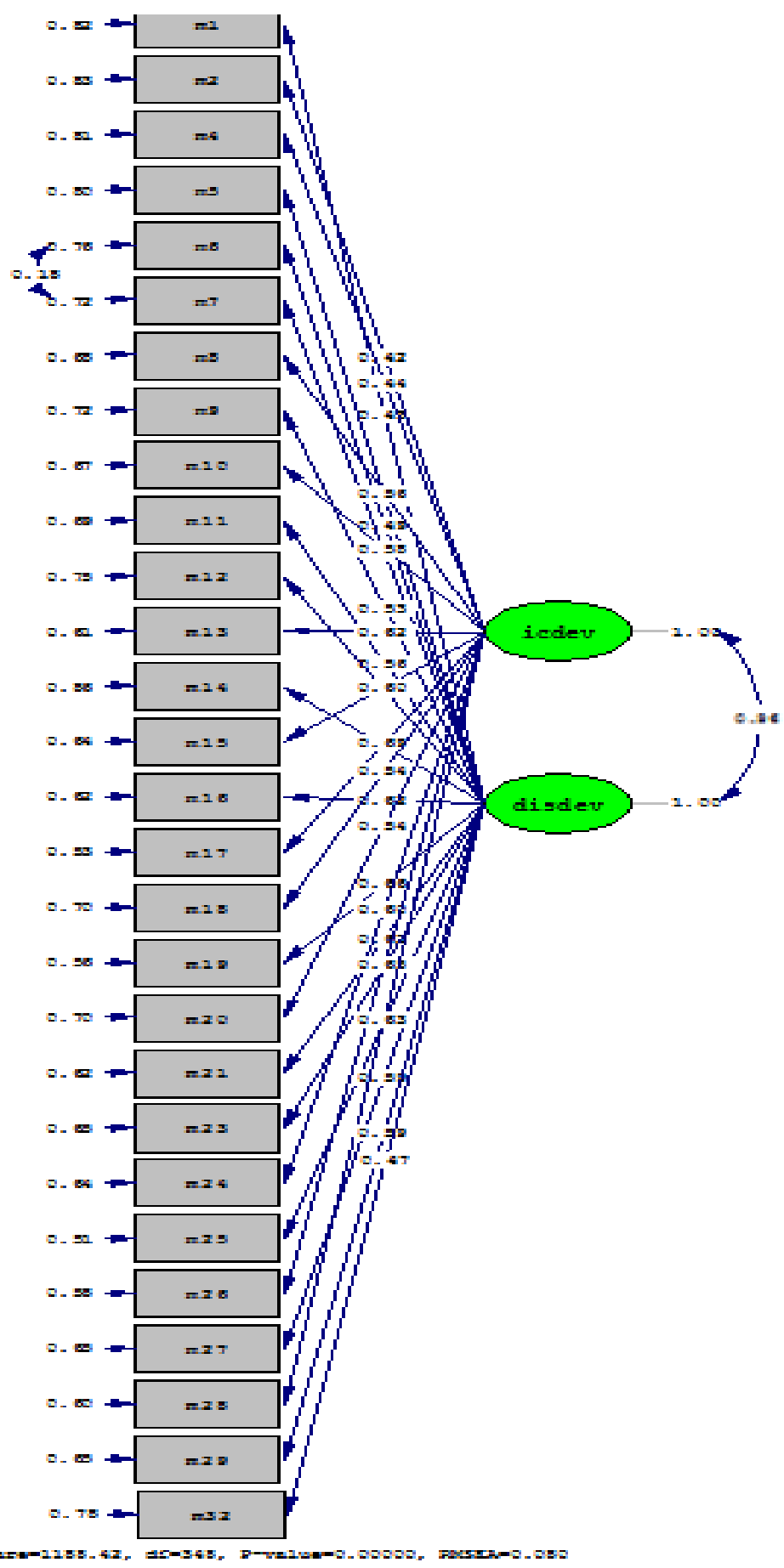

Şekil 2. Öğretmen devamsızlık nedenleri ölçeği DFA (ikinci analiz)

Şekil 2 incelendiğinde, tüm maddelerin standardize edilmiş ilişki katsayılarının (.42 - .69) arasında değiştiği görülmektedir. Ölçeğin $t$ değerleri incelendiğinde ise, (8.23- 14.97) arasında değiştiği ( $t>2.56)$, hata oranının en yüksek (.86) olduğu görülmektedir. DFA uyum değerleri ise Tablo 3 'te verilmiştir. 
Tablo 3.

Öğretmen Devamsızlık Nedenleri Ölçeği Doğrulayıcı Faktör Analizi Uyum Değerleri

\begin{tabular}{lllllllll}
\hline Model & $\chi^{2}$ & $\left(\mathrm{X}^{2} / \mathrm{sd}\right)$ & RMSEA & SRMR & NFI & CFI & GFI & AGFI \\
\hline $\begin{array}{l}\text { Birinci } \\
\text { Düzey }\end{array}$ & 1188.42 & 3.41 & .08 & .06 & .93 & .95 & .82 & .79 \\
\hline
\end{tabular}

DFA ile test edilen modelin Tablo 3'teki uyum indeksleri incelenirken Çokluk vd. (2010, s.271-272)'nin belirttiği uyum değerleri dikkate alınmıştır. Buna göre,

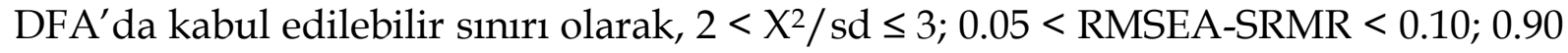
$<$ GFI-NFI < 0.95; $0.95<$ CFI < 0.97; $0.85<$ AGFI < 0.90 (Schermelleh-Engel \& Moosbrugger, Müller, 2003) kabul edilmiştir. Araştırmada elde edilen uyum değerlerinin $\left(X^{2}=1188.42 ; \mathrm{sd}=348 ; \mathrm{X}^{2} / \mathrm{sd}=3.41 ; \mathrm{RMSEA}=.08 ; \mathrm{SRMR}=.06 ; \mathrm{NFI}=\right.$ .93; CFI = .95; GFI = .82; AGFI = .79) genelde kabul edilebilir düzeyde uyum gösterdiği görülmektedir. Bu nedenle elde edilen modelde, faktörlerin veriler ile onaylandığı, ölçeğin iki boyutlu yapısının doğrulandığı ve ölçeğin uygulanabilir olduğu söylenebilir. GFI ve AGFI değerlerinin iyi uyum düzeyinden düşük olmakla birlikte, SRMR değerinin mükemmele yakın olduğu, RMSEA, NFI ve CFI değerlerinin iyi uyum düzeyinde olduğu söylenebilir.

\section{Güvenirlik}

Öğretmen Devamsızlık Nedenleri Ölçeğinin güvenirliğinin hesaplanmasında hem AFA analizi için elde edilen veriler (1. Uygulama $n=415)$ hem de DFA analizi için elde edilen veriler (2. Uygulama $n=380)$ kullanılmıştır. Analiz neticesinde ölçeğin genelinin ve boyutlarının Cronbach Alpha değerleri Tablo 4'te gösterilmiştir.

Tablo 4.

Öğretmen Devamsızlık Nedenleri Ölçeğinin Cronbach Alpha Güvenirlik Katsayıları

\begin{tabular}{lll}
\hline & Uygulama 1 & Uygulama 2 \\
& Cronbach Alpha & Cronbach Alpha \\
\hline Ölçeğin Geneli & .94 & .92 \\
Dişsal Nedenler & .92 & .87 \\
İçsel Nedenler & .89 & .85 \\
\hline
\end{tabular}

Tablo 4 incelendiğinde, birinci uygulamada ölçeğin genelinin Cronbach Alpha güvenirlik katsayısı .94, ikinci uygulamada, .92 olduğu görülmektedir. Özdamar'a (1999: 522) göre Cronbach Alpha güvenirlik katsayısı 80 ile 1.00 arasında ise ölçeğin güvenirliği yüksektir.

\section{Tartışma, Sonuç ve Öneriler}

Araştırma sonucunda, öğretmen devamsızlık nedenlerini belirlemek için geliştirilen ölçeğin geçerli ve güvenilir bir ölçme aracı olduğu görülmektedir. Öğretmen devamsızlık nedenleri ölçeği 28 madde iki alt boyuttan oluşan beşli likert tipi bir ölçektir. Ölçeğin yapı geçerliği AFA ile belirlenmiştir. 42 maddeden oluşan ölçeğin ilk formunun toplam varyansın \% 35.68'ini açıkladığı tespit edilmiş ve öğretmen devamsızlık nedenleri ölçeğinin iki faktörlü yapısı doğrulanmıştır. Sonrasında uygun olmadığına karar verilen bazı maddeler çıkarıldıktan sonra tekrarlanan AFA de toplam varyansın \% 40’10'unu açıklayan iki boyutlu bir yapı elde edilmiştir. Ardından, 
AFA de elde edilen faktörlerin DFA yapılması sonucunda iyi model uyum değerlerine ulaşılmıştır. Öğretmen devamsızlık nedenleri ölçeğinin geçerliği ve güvenirliği ile ilgili elde edilen bulgular, hem alt boyutlarda hem de genelinde ölçme aracının kabul edilebilir değerlerde olduğunu göstermektedir.

Ölçeği cevaplayan bir öğretmenin soru maddelerine verdiği cevapların sayısal karşılığının yüksek olması o öğretmenin devamsızlık nedenlerine ilişkin algısının yüksek olduğu anlamına gelmektedir. Ölçeği cevaplayanların alacağı en düşük puan 28, en yüksek puan ise 140 dir.

Alanyazın incelendiğinde öğretmen devamsızlı̆̆ının; okulun etkililiğini düşürdüğü (Hackett, 2009), öğrenci başarısını olumsuz etkilediği (Brown ve Arnell, 2012; Clotfelter, Ladd ve Vigdor, 2009, s. 22; Hackett, 2009; Jacobs ve Kritsonis, 2007; Seibert, 2013, s. 7; Smith, 2000), öğrencilerin öğrenme isteklerini kaybetmelerine neden olduğu (Bruno, 2002) görülmektedir. Sınıf yönetiminin en etkili ögesi olan öğretmenler eğitim sisteminin de önemli ve etki gücü yüksek parçalarıdır. Fakat bu etki her zaman olumlu olmayabilir. Örneğin, öğretmenin yaşadığı sıkıntılara bağlı olarak devamsızlığ1 artabilir. Buna bağlı olarak ise, öğrencilerde-okullarda yeni ve daha büyük sorunlar gelişebilir. Bu nedenle öğretmenlerin devamsızlık nedenlerini belirleyerek bu konuda gerekli önlemleri almanın sadece devamsızlık yapan öğretmeni değil, öğrenciyi, okulu ve eğitim sistemini olumlu yönde etkileyeceği söylenebilir. Öğretmen devamsızlığı konusunda Türkiye'deki araştırmalar incelendiğinde bu konuda geliştirilmiş bir ölçek olmadığı görülmektedir. Bu nedenle, geliştirilen ölçek öğretmen devamsızlık nedenleri ile ilişkili olan öğrenci başarısı, okul başarısı, okul iklimi, kurum kültürü, okul yöneticisinin davranışları, okul müdürünün öğretmenlere mobbing uygulaması, iş doyumu, mesleki tükenmişlik, motivasyon gibi konular hakkında yapılacak araştırmalarda kullanılabilir ve yapılacak yeni araştırmaları artırabilir.

\section{Kaynakça}

Altunışık, R., Coşkun, R., Bayraktaroğlu, S. ve Yıldırım, E. (2010). Sosyal bilimlerde araştırma yöntemleri spss uygulamalı (6. baskı). Sakarya: Sakarya Yayıncılık.

As, D. (1962). Absenteeism- a social fact in need of a theory. Acta Sociologia, 6, 278285. https:/ / doi.org/10.1177/000169936200600115

Bakay, M. E. (2014). Öğretmen devamsızlığının incelenmesi: Menderes ilçesi örneği. Ege Ĕ̈itim Dergisi, 15(1), 233-250. https:/ / doi.org/10.12984/eed.37412

Brown, S. L. and Arnell, A. T. (2012). Measuring the effect teacher absenteeism has on student achievement at a "Urban but not too urban:" Title I elementary school. International Journal of Humanities and Social Science, 2(17), 172-183.

Bruno, J. (2002). The geographical distribution of teacher absenteeism in large urban school district settings: Implications for school reform efforts aimed at promoting equity and excellence in education. Education Policy Analysis, 10(32), 1-21. http:/ / epaa.asu.edu/ojs/article/viewFile/311/437 (03.11.2018).

Bryman, A. and Cramer, D. (2001). Quantitative data analysis with SPSS release 10 for Windows: A guide for social scientist. New York: Routledge. https:// doi.org/10.4324/9780203471548

Büyüköztürk, Ş. (2012). Örnekleme yöntemleri [Powerpoint sunuları] http:/ / w3.balikesir.edu.tr/ msackes/wp/wpcontent/uploads/2012/03/BA Y-Final-Konulari.pdf (03.11.2018). 
Büyüköztürk, Ş. (2017). Sosyal bilimler için veri analizi el kitabı (23. bask1). Ankara: A Pegem Akademi. https:/ / doi.org/10.14527/9789756802748

Can, A. (2016). Spss ile bilimsel araştırma sürecinde nicel veri analizi (4. baskı). Ankara: A Pegem Akademi.

Chapman, D. (1994) . Reducing teacher absenteeism and attrition: Causes, consequences and responses. Paris: UNESCO.

Clotfelter, C., Ladd, H. and Vigdor, J. (2009). Are teacher absences worth worrying about in the U.S.? (Working Paper No. 24). http:/ / www.caldercenter.org (03.11.2018)

Çokluk, Ö., Şekercioğlu, G. ve Büyüköztürk, Ş. (2010). Sosyal bilimler için çok değişkenli istatististik spss ve lisrel uygulamaları. Ankara: A Pegem Akademi.

Erdemli, Ö. ve Güner-Demir, T. (2015). Eğitim kalitesinde önemli bir engel: Öğretmen devamsızlığı. İ. Aydın ve Ş. Çınkır (Eds.), Prof. Dr. Ethem Başaran'a armă̆an, eğitimde 52 yıl (s. 420-436). Ankara: Anı Yayıncılık.

Gibson, R. O. (1966). Toward a conceptualization of absence behavior of personnel in organizations. Administrative Science Quarterly, 11(1), 107-133. https:// doi.org/10.2307/2391396

Habib, M. (2010). The impact of 2002 national teacher contract policy reform on teacher absenteeism in Lahore, Pakistan (Doctoral dissertation). http:/ / search.proquest.com/pqdtglobal/index.(03.11.2018).

Hackett, R. S. (2009). Teacher absenteeism. http:/ / hdl.handle.net/2139/8983 (03.11.2018).

Harrison, D. A. and Martocchio, J. J. (1998). Time for absenteeism: A 20 year review of origins, offshoots and outcomes. Journal of Management, 24(3), 305-350. https:// doi.org/10.1177/014920639802400303

Hovey, M. R. (1999). Analysis and management of teacher absenteeism in selected school districts of varying sizes in San Bernardino county (Doctoral dissertation). http:/ / search.proquest.com/pqdtglobal/index (03.11.2018)

Jacobs, K. D. and Kritsonis, W. A. (2007). An analysis of teacher and student absenteeism in urban schools: What the research says and recommendations for educational leaders. http:/ / files.eric.ed.gov/ fulltext/ED499647.pdf (03.11.2018).

Kline, P. (1994). An easy guide to factor analysis. New York: Routledge

Nicholson, N. and Johns, G. (1985). The absence culture and the psychological contract: Who is in control of absenteeism. Academy of Management Review, 10(3), 397-407.

Özdamar, K. (1999). Paket programlar ile istatiksel veri analizi I. (2. baskı). Eskişehir: Kaan Kitabevi.

Robinson, C. M. (2008). Teacher absenteeism: Its relationship to student performance on state assessments in english/language arts in grades three, five, and seven (Doctoral dissertation).https://fisherpub.sjfc.edu/cgi/viewcontent.cgi?referer=https:// wwwgoogle.com.tr / \&httpsredir=1\&article=1084\&context=education_etd (03.11.2018).

Ryan, R. M. and Deci E. L. (2000) Intrinsic and extrinsic motivations: classic definitions and new directions. Contemporary Educational Psychology, 25(1), 5467. https:/ / doi.org/10.1006/ceps.1999.1020 
Schermelleh-Engel, K., Moosbrugger, H. and Müller, H. (2003). Evaluating the fit of structural equation models: Tests of significance and descriptive goodness-offit measures. Methods of Psychological Research Online, 8(2), 23-74.

Seçer, İ. (2015). Psikolojik test geliştirme ve uyarlama süreci: SPSS ve LISREL uygulamaları. Ankara: Anı Yayıncilık.

Seibert, J. C. (2013). Study of the perceptions of middle school principals on teacher absenteeism within an urban school district (Doctoral dissertation). http:/ / search.proquest.com/pqdtglobal/index (03.11.2018).

Sezgin F., Koşar S., Kılınç, A. Ç. and Öğdem, Z. (2014). Teacher absenteeism in Turkish Primary schools: A qualitative perspective from school principals. International Online Journal of Educational Sciences, 6(3), 612-625. https:/ / doi.org/10.15345/iojes.2014.03.010

Smith, G. G. (2000). Increasing teacher attendance: Substitute Teaching Institute. Subjournal, 2(1), 8-17.

Steers, R. M. and Rhodes, S. R. (1978). Major influences on employee attendance: A process model. Journal of Applied Psychology, 63(4), 391-404. https:// doi.org/10.1037/0021-9010.63.4.391

Şahin, F. (2011). İşe devamsızlı̆̆ın nedenleri, sonuçları ve örgütler için önemi. Niğgde Üniversitesi İ̈BF Dergisi, 4(1), 24-39.

Tabachnick, B. G. and Fidell, L. S. (2001). Using multivariate statistic (Fourth Edition). MA: Allyn \& Bacon, Inc.

Tavşancıl, E. (2010). Tutumların ölçülmesi ve SPSS ile veri analizi. Ankara: Nobel Yayın Dağıtım.

The World Bank (2011). Improving the quality and equity of basic education in Turkey challenges and options (Report No. 54131-TR). Retrieved from http:/ / documents.worldbank.org/curated/en/105971468338992381/pdf/541 310SR0P107700Quality0Report02011.pdf (03.11.2018).

\section{Summary}

\section{Introduction}

Since the concept of absenteeism is defined in different ways by many researchers, it is difficult to find a common definition of absenteeism in the literature that all researchers agree on (Erdemli \& Güner-Demir, 2015, s. 420). It is seen that in the research, the concept of absenteeism is generally used on the subject of discontinuity. The most general definition of absenteeism is that the employee is not physically present at work (Şahin, 2011).

In reviews which are made, it is seen that teacher absenteeism is the topic of limited number of studies (Bakay, 2014; Erdemli \& Güner-Demir, 2015; Sezgin vd., 2014) in Turkey and in these studies, it is not found a scale which is developed to determine the causes of teacher absenteeism. For this reason, it is thought that a valid and reliable scale which will be developed about teacher absenteeism will be an effective tool in determining the causes of teacher absenteeism. It is considered that this scale which will be developed will contribute to the increase of studies about teacher absenteeism. 


\section{Method}

This research which was conducted in the survey model was carried out in the province of Antalya and Burdur in the 2017-2018 academic year with the method of convenience sampling. The total number of participants in the study is 862 . Exploratory factor analysis (EFA) was conducted to determine the construct validity of the scale and confirmatory factor analysis was conducted to test the accuracy of the factor structure which was obtained as a result of this analysis. Expert opinion was consulted for the content validity of the scale. In the examining of the reliability of the scale, the coefficient of the internal consistency and the coefficient of the split-half test reliability were calculated. In addition, item total correlations of the scale were examined before factor analysis. The model fit of the scale which was obtained in EFA was examined by conducting CFA. Multiple fit indices were used in CFA. The research process was carried out in consecutive stages.

\section{Findings, Discussion and Results}

Based on the result of this study, it can be said that this scale which was developed to determine the causes of teacher absenteeism is valid and reliable. The causes of teacher absenteeism scale is 5 point likert type scale which consists of 28 items and two subdimensions. In the last form of this scale which was obtained as a result of the exploratory and confirmatory factor analyses, the dimension of the internal causes of absenteeism consists of the items of $2,3,7,9,12,14,16,17,19,22,24,26$; the dimension of the external causes of absenteeism consists of the items of 1, 4, 5, 6, 8, 10,11, 13, 15, $18,20,21,23,25,27,28$. The construct validity of the scale was determined by EFA. The first form of the scale which consisted of 42 items explained $35.68 \%$ of the total variance and two-factor structure of the causes of teacher absenteeism scale was confirmed. After the removal of some items which were decided to be unsuitable, two dimensional structure which explained $40.10 \%$ of the total variance was obtained in the repeated EFA. Subsequently, good model fit values were reached as a result of confirmatory factor analysis of the factors which were obtained in the exploratory factor analysis. Findings which were obtained about the validity and reliability of the causes of teacher absenteeism scale indicated that the measurement tool was in acceptable values. Being at a high rate of these values which are obtained can be interpreted in the way that the causes of teacher absenteeism scale is reliable. For this reason, it is expected that the developed scale can be used in the research on this issue and can increase the number of new studies to be done.

\section{Araştırmanın Etik Taahhüt Metni}

Yapılan bu çalışmada bilimsel, etik ve alıntı kurallarına uyulduğu; toplanan veriler üzerinde herhangi bir tahrifatın yapılmadığı, karşılaşılacak tüm etik ihlallerde "Cumhuriyet Uluslararası Eğitim Dergisi ve Editörünün" hiçbir sorumluluğunun olmadığı, tüm sorumluluğun Sorumlu Yazara ait olduğu ve bu çalışmanın herhangi başka bir akademik yayın ortamına değerlendirme için gönderilmemiş olduğu sorumlu yazar tarafından taahhüt edilmiştir. 


\section{Authors' Biodata/ Yazar Bilgileri}

Şerife TÜRKKAN lisans eğitimini Kocaeli Üniversitesi İngiliz dili ve edebiyatı bölümünde tamamlamıştır. Yüksek Lisansını Mehmet Akif Ersoy Üniversitesi eğitim yönetimi alanında yapmıştır. Halen Milli Eğitim Bakanlığında müdür yardımcısı olarak görev yapmaktadır.

Şerife Türkkan received her BA in the department of English Language and Literature at Kocaeli University. She received her MA in the field of educational administration at Mehmet Akif Ersoy University, Turkey. She is still working as a deputy principal at the Ministry of Education.

Öznur TULUNAY ATEŞ lisans eğitimini Ondokuz Mayıs Üniversitesi psikoloji bölümünde tamamlamıştır. Yüksek Lisansını Kırıkkale Üniversitesi eğitim yönetimi alanında yapmıştır. Doktorasını Gazi Üniversitesi eğitim yönetimi alanında yapmıştır. Halen Mehmet Akif Ersoy Üniversitesi Eğitim Fakültesinde Doçent olarak görev yapmaktadir.

Öznur Tulunay Ateş received her BA in the department of Psychology at Ondokuz Mayıs University. She received her MA in the field of educational administration at Kirıkkale University. She received her $\mathrm{PhD}$ in the field of educational administration at Gazi University, Turkey. She is still working as an Associate Professor in the Faculty of Education at Mehmet Akif Ersoy University. 